\title{
Root contribution to stay-green in rice (Oryza sativa L.) subjected to desiccated soils in the post-anthesis period
}

\author{
Tien Ba HOANG and Tohru KOBATA*
}

Faculty of Life and Environmental Science, Shimane University

\begin{abstract}
The stay-green trait as a maintenance capacity of green leaves assimilating under desiccated soils in the post-anthesis period is known in several crop plants. Our objectives were to clarify if the capacity to stay green in the terminal growth stage is related to root performance in Vietnam rain-fed rice cultivars. Three Vietnam cultivars were grown under flood conditions in 130-L volume pots. Irrigation was withheld from half of the pots at the anthesis period, while the flood condition was maintained in the remaining pots. The SPAD value as an indicator of green color, green leaf area (GLA) and leaf conductance $\left(\mathrm{C}_{\mathrm{L}}\right.$ ) decreased after heading, but trends of the decrease by soil desiccation differed among cultivars. The cultivar, which showed higher maintenance of the SPAD value, GLA and $C_{L}$ under desiccated soils, had significantly denser roots in the surface soil layer at harvest. The water absorption rate per soil volume and per root length of almost all soil layers in the cultivar was maintained longer and higher in desiccated soils. The SPAD value and GLA of detached leaves in the cultivar incubated under dark and humid conditions were maintained significantly longer. This showed that the leaf properties contribute to the maintenance of green leaves. These results suggest that in stay-green rice cultivars the properties that keep the leaves green contribute to a delay in the suppression of assimilate processes and maintain the water absorption function of the roots by maintaining the assimilate supply to roots.
\end{abstract}

Keywords: leaf conductance, roots, stay- green, water absorption

\section{Introduction}

Rice in rain-fed areas of the Southeast Asian country of Vietnam is prone to drought (Barker and Herdt 1979; Vietnam News 2007). Overcoming the effects of drought on rice yield in these areas has been expected by agriculturalists (Barker and Herdt 1979), but the yield improvement of rain-fed rice in Vietnam has only been from 2.7 to $3.3 \mathrm{t}$ or less per ha during the past several decades ( $\mathrm{Yo}^{-}$ shida 1981, GSO 2007).

There are several drought resistant mechanisms in rice, as in other crops (Turner 1979). One of the most effective mechanisms in rice should be drought avoidance by which plants can develop deep root systems, which use water from deep soil layers, thus enabling plants to avoid plant dehydration (Kobata et al. 1996). Drought tolerance is important for seedling survival in young rice plants with poor root development (O'Toole and Chang 1979, Ahmad et al. 1987). The stay-green trait is one of the most effective drought resistant traits in sorghum and wheat, and is suggested to be a trait related to the drought tolerances of dehydrated plants. Stay-green is the capacity to maintain green leaves for photosynthetic activity (Thomas and Smart 1993), and is considered one of the ways by which grain yield is maintained under drought in sorghum (Borrell et al. 2000a, Borrell et al. 2000b, Borrell and Hammer 2000, Mahalakshmi and Bidinger 2002) and in wheat (Christopher et al. 2004). Stay-green under drought conditions is suggested to be related not only with leaf traits but with root ones that absorb water or nutrients. Roots of stay green cultivars in sorghum had a greater capacity to extract nitrogen from the soil to balance the requirement of nitrogen from grain during the grain-filling period than the roots of non-stay green ones (Borrell et al. 2001).

Root development in cereals generally stops at the flowering period, and thus the plant has to use soil water around roots under low rainfall conditions (Yoshida and Hasegawa 1982, Gregory 1994). 
Furthermore, because rain-fed lowland fields have soil hardpan formed in a shallow soil depth (Dexter and Woodhead 1985, Sharma and De Datta 1985, Samson et al. 2002) by the tillage of wet soil, the roots do not penetrate into deep soils and the soil volume that roots can access as a water source is limited (Barker and Herdt 1979, Hasegawa et al. 1985, Thangaraj et al. 1990). It was observed that some rice cultivars from rain-fed lowland areas in Vietnam maintain green leaves and matter production under dry soils (Hoang and Kobata 2009). However, the root function in stay-green cultivars in rice under desiccated soil is not well known. Our objective was to find out whether stay-green trait in rice under desiccated soils is related to root performance in Vietnam rain-fed cultivars.

\section{Materials and Methods}

\section{Plant responses to desiccated soils and root growth}

\subsection{Plant materials}

Three Vietnam lowland rice cultivars, Nep dap, Khau nua han and Khau lech were used. These cultivars were selected from 24 cultivars in trials for comparison of the stay-green capacity in drought prone areas (Hoang and Kobata 2009). In the trial, Nep dap showed relatively high stay-green capacity, Khau nua han an intermediate capacity, and Khau lech the lowest. Experiments were conducted at the experimental farm of Shimane University, at $35^{\circ} 28^{\prime} \mathrm{N}, 133^{\circ} 02^{\prime} \mathrm{E}$ in Japan.

Germinated seeds of the three cultivars were sown in seedling beds $(0.60 \times 0.30 \times 0.03 \mathrm{~m})$ on April 14 and 19, 2008 and on May 7, 2008, respectively. On May 9 and 14, 2008, and June 1, 2008, twenty seedlings at the four-leaf stage of Nep dap, Khau nua han and Khau lech were circle-transplanted to polyethylene pots with a diameter at the surface of $56 \mathrm{~cm}$, a diameter at the bottom of $38 \mathrm{~cm}$, and height of $75 \mathrm{~cm}$ (about 130-L in volume). The pots were filled with Andosol rice seedling soil (Green Epoch Co., Izumo, Japan) to a depth of $65 \mathrm{~cm}$. Before the seedlings were transplanted to the pots, $5 \mathrm{~g}$ ammonium sulfate, $12 \mathrm{~g}$ superphosphate of lime and $4 \mathrm{~g}$ potassium chloride was applied as a basal fertilizer in the surface soils at a depth of $0.15 \mathrm{~m}$. All pots were placed in a non-temperature-controlled glasshouse and watered daily to maintain the flood condition in the pots.
The photoperiod treatment was carried out because the cultivars were photoperiodically sensitive. From July 8, 2008, to August 5, 2008, the plants were put in a shelter at 17:00 pm and taken out at 07:00 am the next day. The shelter was a steel frame $(3.60 \times 1.80 \times 2.20 \mathrm{~m})$ covered with a black vinyl sheet, and had a temperature-controlled fan that drew air to the outside to reduce air temperature inside the shelter. When booting was observed, the treatment was finished and the pots were moved out of the shelter. The heading date in Khau nua han and Khau lech were August 11, while in Nep dap it was 10 days later.

\subsection{Soil desiccation treatment}

The pots were separated into two groups, irrigated and desiccated pots. Watering was withheld from half of the pots for 30 days after heading, while a flood condition was maintained in the remaining pots. The temperature and humidity were measured and logged with a data logger every $30 \mathrm{~min}$.

\subsection{Measurements}

\subsubsection{Soil water content and water absorption rate}

Every three days, the soil water content (SWC, g $\mathrm{cm}^{-3}$ ) at a $0.1,0.2,0.3$ and $0.4 \mathrm{~m}$ depth from the soil surface was measured with a TDR soil moisture sensor and data reader (PP2 and HH2, Delta-T Devices Ltd., Cambridge, UK).

Water absorption (WA, $\mathrm{g} \mathrm{cm}{ }^{-3} \mathrm{kPa}^{-1}$ ) for each interval of three days corrected by vapor deficit to eliminate the effect of humidity on transpiration (Tanner and Sinclair 1983) in each soil layer was calculated as:

$$
\sum\left(\mathrm{SWCx}-\mathrm{SWC}_{0}\right)
$$

where $\mathrm{x}=0,3,6, \cdots \cdots . .30$ (day) and WA was fitted by the exponential equation of days after heading as $y=a /\{1+b \operatorname{Exp}(-c x)\}$. In this equation, $a, b$ and $c$ are parameters decided by curve fitting due to the least-squares method. The water absorption rate (WAR, $\mathrm{g} \mathrm{cm}^{-3} \mathrm{~Pa}^{-1}$ day $^{-1}$ ) in each soil layer was shown by differential calculus of the exponential equation (1) (Milthorpe and Moorby 1979).

$$
\mathrm{WAR}=\{\operatorname{abcExp}(-\mathrm{cx})\} /\{1+\mathrm{b} \operatorname{Exp}(-\mathrm{cx})\}^{2}
$$

\subsubsection{Leaf color, green leaf area and leaf con- ductance}

Every three days after the start of the soil des- 
iccation treatment, the leaf green color (SPAD value) and visual green color leaf area $\left(\mathrm{GLA}, \mathrm{cm}^{2}\right)$ were measured for five upper leaves. The SPAD value was an average value of three positions of the leaf blade measured with a portable chlorophyll meter (SPAD-502, Minolta Co., Ltd., Tokyo). The GLA was determined as follows:

$$
\mathrm{GLA}=\mathrm{GLA}_{0} \times(1-\mathrm{SLAR} / 100)
$$

where GLA $_{0}$ is GLA at the start of soil desiccation for the area of each of the five upper leaves measured with a leaf area meter (CI-203 area meter, CID, Inc., Vancouver, WA, USA), and SLAR is the percentage of senesced leaf area in each leaf. The senesced leaf area is defined as an area of leaf that is occupied by yellow or white portions by degradation of chlorophyll pigment. SLAR was visually scored on a $0-$ to $^{-9}$ scale for leaves of each position from three tillers per plant, where $0=0 \%$ to $10 \%$ of the senesced leaf area and $9=90 \%$ to $100 \%$ of the senesced leaf area. The GLA for the five leaves was accumulated as the green leaf area for the whole plant.

Leaf conductance $\left(\mathrm{C}_{\mathrm{L}}\right)\left(\mathrm{cm} \mathrm{s}^{-1}\right)$ was measured at the center of the abaxial leaf surface of the uppermost two leaves over a light strength of $1000 \mu$ mol $\mathrm{cm}^{-2} \mathrm{~s}^{-1}$ with a diffusion porometer (Delta-T AP4, Devices Ltd., Cambridge, UK). The measurement was made at 10:00 am on clear sunny days in two tillers of two hills in each pot.

\subsubsection{Root length density}

At harvest, soil cores $40 \mathrm{~cm}$ in length and $5 \mathrm{~cm}$ in diameter in each desiccated pot were taken from two positions with a liner sampler (Eijkelkamp, Agrisearch Equipment, P.O. Box 4, 6987 ZG Giesbeek, The Netherlands), which is a stainless steel sample tube with a length of $35 \mathrm{~cm}$ and a diameter of $5 \mathrm{~cm}$. After the first sampling of soil core the sampler was put into the hole of the first sampling to take the deeper soil core. One position was below the plant hill and the other was in the center between the plant hills and the center of the pot. These soil cores were cut and divided into 4 layers $(10,20,30$ and $40 \mathrm{~cm})$, and then each soil layer was kept in a labeled bag. The soil layer was carefully washed out the soil particle by tap water to preserve the root hair. The procedures for measuring the root length were carried out as described by Kimura et al. (1999). The root samples were pre- served in $70 \%$ alcohol, stained dark blue with $0.25 \%$ Coomassie Brilliant Blue $\mathrm{R}$, cut into segments of about $3 \mathrm{~cm}$ and then floated in shallow water $(2-4$ $\mathrm{mm}$ ) in a clear acrylic resin tray. The tray with root segments was then scanned with an image scanner (HP ScanJet, Hewlett-Packard Co., USA) equipped with an illumination unit (HP Transparency Adapter, Hewlett-Packard Co., USA), at $200 \mathrm{dpi}$ and digitized signals were transmitted to a personal computer (Power Macintosh G3, USA), where the root images were stored. For measurement of root length, NIH Image ver. 1.60 software (developed at the US National Institute of Health) on a personal computer (Power Macintosh 7200/120, Apple Computer, Inc.) was used.

\subsubsection{Experimental design and statistical analy- sis}

The experiment design was completely randomized with two replications. ANOVA was used to test significant differences.

\section{Comparison of maintenance of green leaves by incubation of detached leaves}

\subsection{Plant materials}

The same three cultivars used for the soil desiccation experiments were used. Four seedlings of the cultivars grown in the same manner as in the pot experiment were transplanted into a plastic pot filled with $4-\mathrm{L}$ of Andosol. Before transplantation, $0.5 \mathrm{~g}$ ammonium sulfate, $1.2 \mathrm{~g}$ superphosphate of lime and $0.3 \mathrm{~g}$ potassium chloride was applied as a basal fertilizer. All pots were placed in a non-temperature-controlled glasshouse and watered daily to maintain the flood condition. The photoperiod treatment was carried out in the same manner as in the soil desiccation experiments.

\subsection{Leaf incubation treatments and measure- ments}

At heading, the SPAD value of the three uppermost leaves was measured, and the leaves were then cut, put in plastic bags with water and immediately brought to the laboratory. The leaves were floated in air-tight plastic trays containing distilled water. The trays were covered with aluminum foil to keep the leaves in a dark condition and then placed in temperature-controlled incubators at $25^{\circ} \mathrm{C}$. Every 3 days after the start of incubation, the SPAD value and GLA were monitored in the 
same manner as in the soil desiccation experiment. The experiment was stopped when the leaves of any among the three cultivars had almost lost green color. On the final day of the experiment, the leaf area was measured with a leaf area meter.

\subsection{Experimental design and statistical analysis}

The experimental design was completely randomized with three replications. ANOVA was used to test significant differences as Turkey's LSD.

\section{Results}

1. Plant responses to desiccated soils 1.1. SWC, SPAD value, GLA and $C_{L}$

After heading SWC of the soil layers between 10 $\mathrm{cm}$ and $40 \mathrm{~cm}$ in the three cultivars in the desiccation pots was reduced. However, the SWC for Khau nua han at heading was a little higher than that for the other two cultivars (Fig. 1). The reduction of SWC in each soil layer from 6 days and 18 days after heading was more moderate in Nep dap than in Khau nua han and Khau lech. The trend in each soil layer was reflected to SWC of the entire soil layer (Fig. 1). After 18 days from heading, the SWC in all cultivars decreased similarly, ending at between 0.11 and $0.12 \mathrm{~g} \mathrm{~cm}^{-3}$ (Fig. 1).

After heading, the SPAD value and GLA in three cultivars decreased regardless of irrigation, but the decrease in the desiccated plants was larger than in the irrigated plants (Fig. 2). The SPAD value in Nep dap started to decrease 12 days after heading, which was 3 days later than in Khau nua han and Khau lech. At 12 days after heading, the SPAD value in Nep dap under desiccated soils remained, but the green color in Khau lech was completely lost. The GLA in Nep dap and Khau nua han started to reduce around two weeks after heading, and within one week after heading in Khau lech. The green leaves in Khau nua han and Khau lech were completely lost at 18 and 14 days after heading, respectively (Fig. 2).

$\mathrm{C}_{\mathrm{L}}$ in all cultivars decreased after heading $\mathrm{re}^{-}$ gardless of irrigation, while in Nep dap at heading it was significantly higher than the other two cultivars (Fig. 2.). Suppression of $\mathrm{C}_{\mathrm{L}}$ by soil desiccation in Nep dap was not observed at all, but $C_{L}$ in Khau nua han and Khau lech was significantly suppressed (Fig. 2).
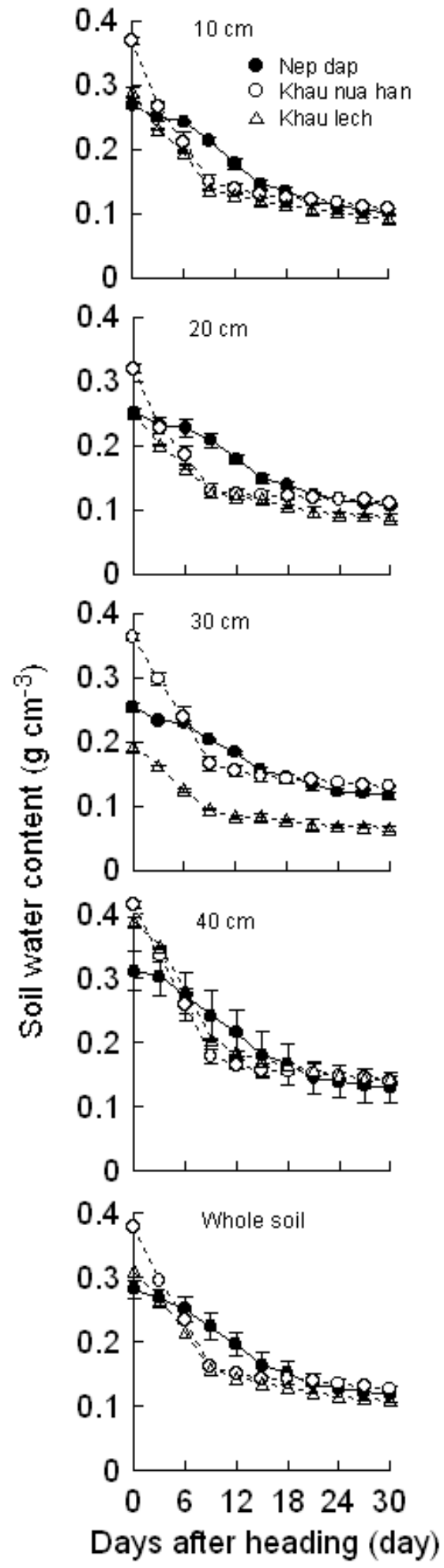

Fig. 1. Soil water contents in four different soil depths and through the entire depth in three Vietnam rice cultivars, Nep dap, Khau nua han and Khau lech when water was withheld from the soils at heading. Each data is mean \pm standard error for two replications. Standard error over size of symbols is omitted for clarify. 
1.2. Root length density and water absorption

The root length density at harvest in the shallow soil layer between 0 and $10 \mathrm{~cm}$ from the soil surface in plants subjected to desiccated soils was significantly higher in Nep dap than in Khau nua han and Khau lech, but no difference was observed in the deeper soil layers (Fig. 3).

The amounts of water absorption from each soil layer were calculated (eq. 1) from the day trend data of the SWC profile (Fig. 1) when water movement between the soil layers was ignored. To eliminate the effects of different vapor deficits on water absorption due to different evaporative demand among cultivars (Tanner and Sinclair 1983), the water absorption of each soil layer per three-day interval was corrected by the vapor deficit of the term. For each cultivar, the accumu-
Root length density $\left(\mathrm{cm} \mathrm{cm}^{-3}\right)$

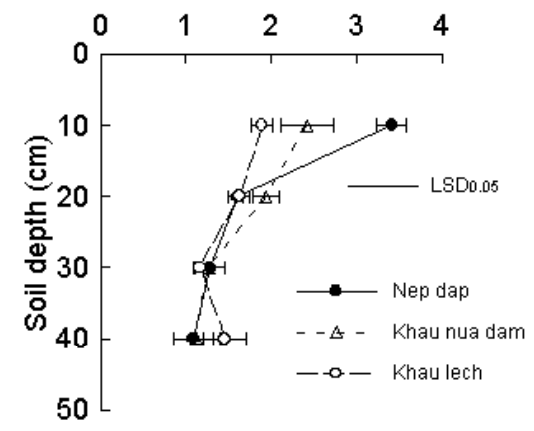

Fig. 3. Root length density at four different soil depths and in total soil depth in three Vietnam rice cultivars, Nep dap, Khau nua han and Khau lech, when water was withheld from the soils at heading Each data is mean \pm standard error for two replications. Lateral bar indicates $\mathrm{LSD}_{0.05}$ by Turkey test.

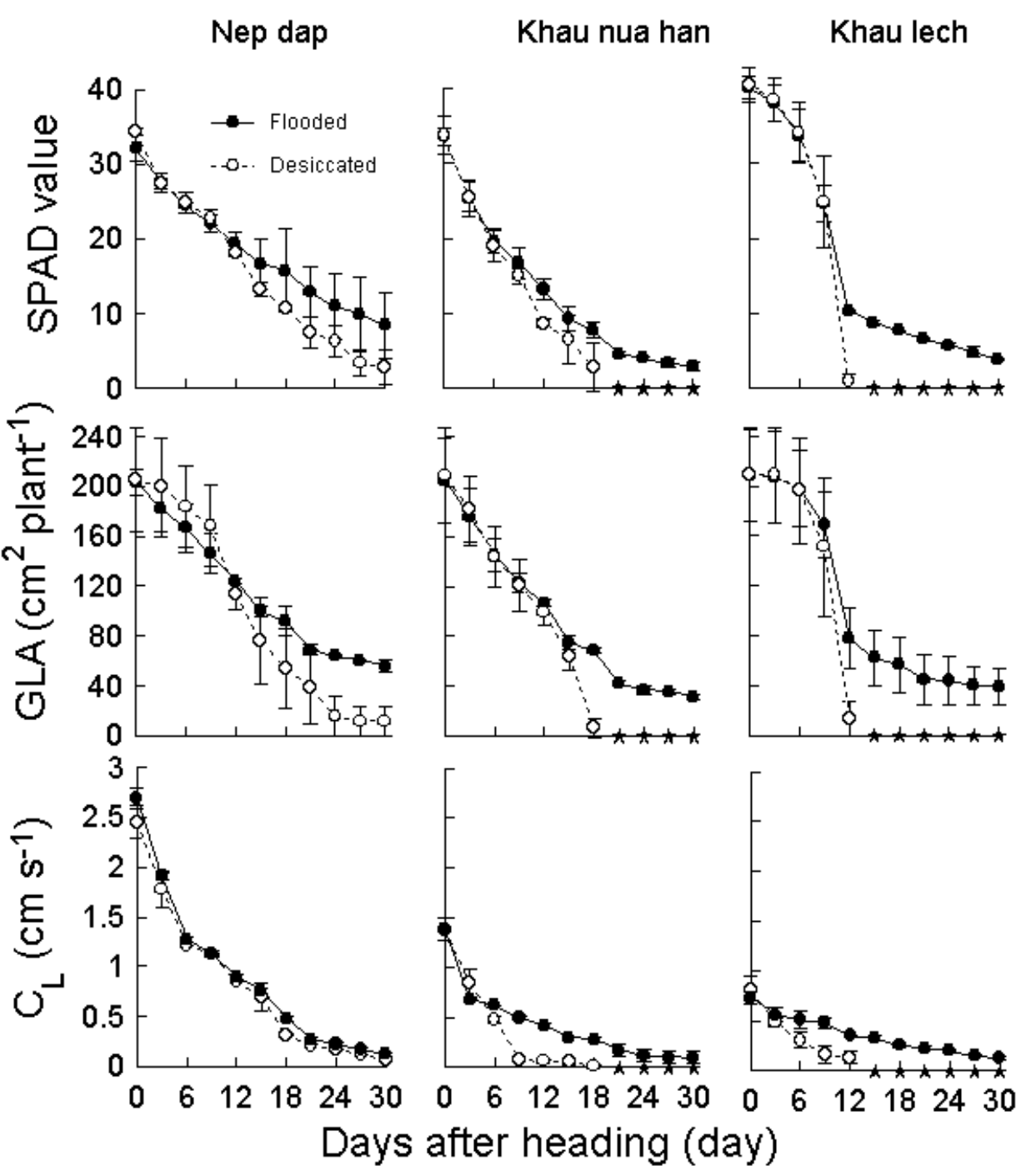

Fig. 2. SPAD value, green leaf area (GLA) and leaf conductance $\left(C_{L}\right)$ in three Vietnam rice cultivars subjected to flooded and desiccated soil conditions for 30 days after heading. Each data is mean \pm standard error of two replications. Standard error over size of symbols is omitted for clarify. Close star symbols indicate no data because of complete leaf death. 
lated amounts of absorbed water per vapor deficit in each soil layer are shown (Fig. 4). The amounts of absorbed water in all soil depths from heading to harvest was higher in Nep dap than in the other two cultivars.

When the equation of the accumulated absorbed water (eq. 1) was differentiated (eq. 2) to find out the water absorption rate, the peak of the rate in Nep dap in all soil layers appeared later than in the other two cultivars, and as a result, the water absorption rate in Nep dap was maintained longer

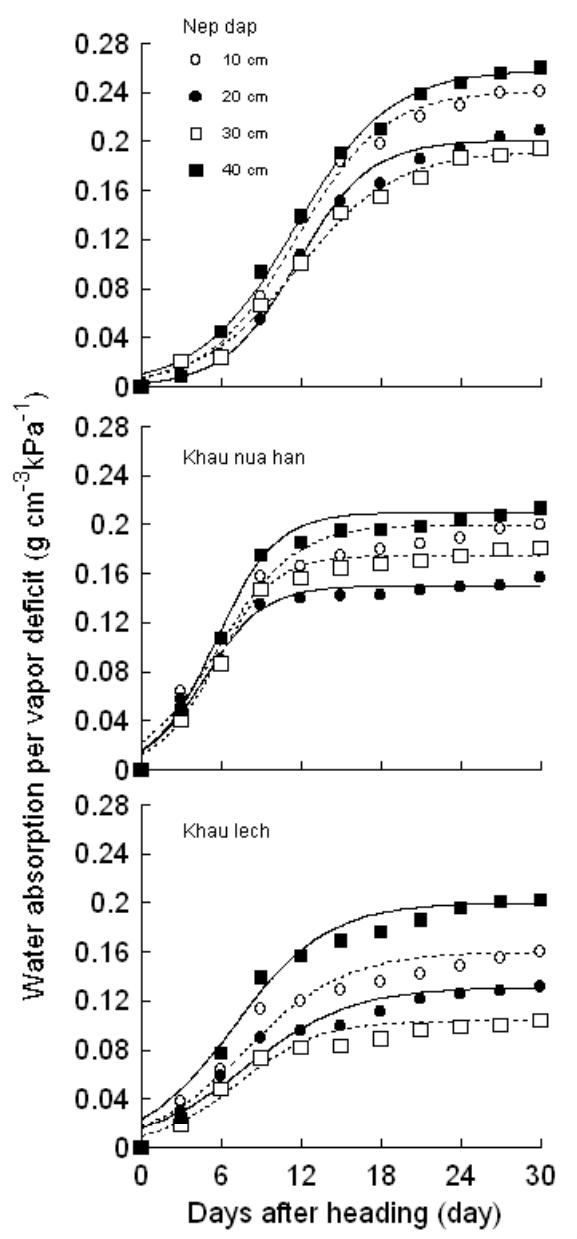

Fig. 4. Trends of water absorption in four different soil layers $(10,20,30$ and $40 \mathrm{~cm})$ in Vietnam rice cultivars, Nep dap, Khau nua han and Khau lech in desiccated plots for 30 days after heading. When $y=a /\{1+b \operatorname{Exp}(-c x)\}, a=0.24, b=34.50, c=0.30$ at 10 $\mathrm{cm} ; \mathrm{a}=0.20, b=71.15, \mathrm{c}=0.36$ at $20 \mathrm{~cm} ; \mathrm{a}=0.14$, $b=24.34, c=0.27$ at $30 \mathrm{~cm} ; a=0.26, b=25.15, c=0.28$ at $40 \mathrm{~cm}$ in Nep dap, $a=0.20, b=7.78, c=0.35$ at $10 \mathrm{~cm} ; a=0.15, b=8.81, c=0.45$ at $20 \mathrm{~cm} ; a=0.18$, $b=12.90, c=0.45$ at $30 \mathrm{~cm} ; a=0.21, b=12.24, c=0.45$ at $40 \mathrm{~cm}$ in Khau nua han and $a=0.16, b=8.38$, $c=0.27$ at $10 \mathrm{~cm} ; a=0.13, b=7.28, c=0.25$ at $20 \mathrm{~cm}$; $a=0.10, b=10.50, c=0.33 ; a=0.20, b=7.56, c=0.29$ in Khau lech. under desiccated soils (Fig. 5). The water absorption rate in Nep dap reached the maximum at 12 days after heading, and then decreased to near 0 at 30 days after heading, while in Khau nua han and Khau lech it reached the maximum rate at 6 days after heading, and then decreased to near 0 at 18 days in Khau nua han and at 21 days in Khau lech. When the rate was indicated by a rate per root length, the difference in the rate among cultivars in all soil layers was reduced and the trends of the rate for the cultivars were unchanged (Fig. 5).

The total amounts of absorbed water corrected by vapor deficit per root length through soil depth for 30 days during the grain-filling period was higher in Nep dap than in the other two cultivars (Fig. 6).

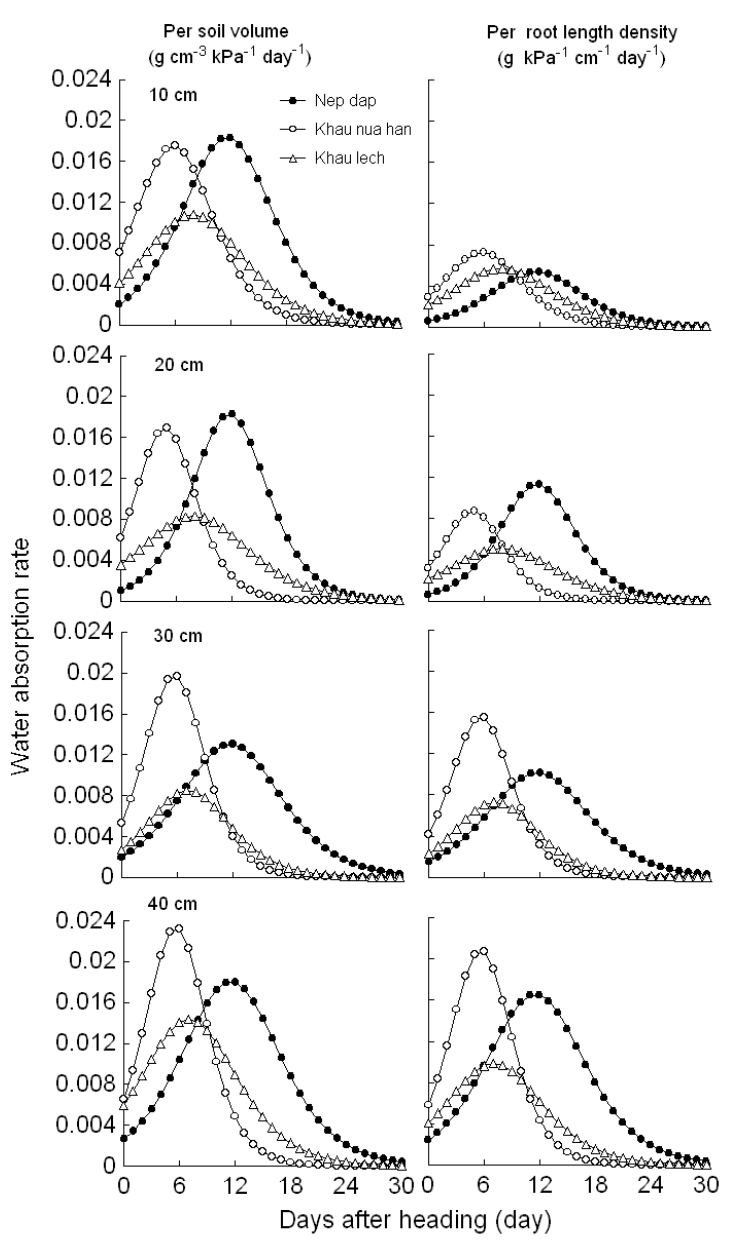

Fig. 5. Water absorption rate in soil volume and root length density in different soil layers in Vietnam rice cultivars Nep dap, Khau nua han and Khau lech in desiccated plots for 30 days after heading. The rate was calculated from Fig. 4. 


\section{Maintenance of green leaves in incubated detached leaves}

When the three detached upper leaves in the three cultivars were incubated under a dark and humid condition, decreases in the SPAD value and GLA in Nep dap after the start of incubation were significantly slower than in Khau nua han and Khau lech (Fig. 7).

\section{Discussion}

If both green leaves and the assimilation process in the green leaves can be maintained under des$^{-}$ iccated soils, stay-green will be effective for plant productivity. This is regarded as functional stay-green (Thomas and Howarth 2000). Photosynthesis of leaves consists of several $\mathrm{CO}_{2}$ diffusion and fixation processes (Jones 1983). In our research, the photosynthetic rate was not monitored, but $\mathrm{C}_{\mathrm{L}}$ was. In rice, however, $\mathrm{C}_{\mathrm{L}}$, a diffusion pathway from the atmosphere to interior of the leaf for $\mathrm{CO}_{2}$, is the most predominant process for $\mathrm{de}^{-}$ ciding the net photosynthetic rate in leaves suffering from leaf dehydration under diverse soil moisture conditions, except under remarkably severe desiccated soils (Hirasawa et al. 1989). Hence, the maintenances of $\mathrm{C}_{\mathrm{L}}$ strongly suggested that leaf photosynthesis would be maintained particularly well in the moderate soil desiccation, although a photosynthetic process for chloroplast in severe dehydrated leaves was not checked in our study. In present study, Nep dap which can keep the SPAD value, GLA and $C_{L}$ under desiccated soils would be regarded as a stay-green cultivar. Furthermore,

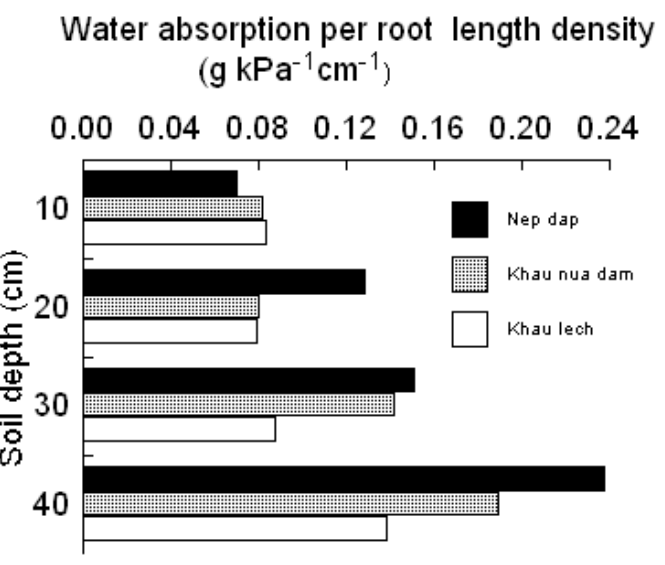

Fig. 6. Total amounts of absorbed water in the post-anthesis period per root length in different soil layers in the Vietnam rice cultivars Nep dap, Khau nua han and Khau lech in desiccated plots for 30 days after heading. the incubated experiments for detached leaves under wet conditions suggested that Nep dap has a higher green leaf maintenance capacity than the other two cultivars although terms for the maintenance in the incubated leaves was much shorter than in leaves of the soil desiccated experiment (Fig. 7). The trends for the maintenance of SPAD value and GLA among the leaves detached from the three cultivars approximately coincided with the trends in plants subjected to desiccated soils during the grain-filling period (Fig. 2).

The maintenance of green leaves in rice during the grain-filling period might be affected not only by the leaf function for a delay of leaf senescence but by the strength of the requirement for assimilate or nitrogen in grains. The detached leaves were not affected by the requirement in grains and
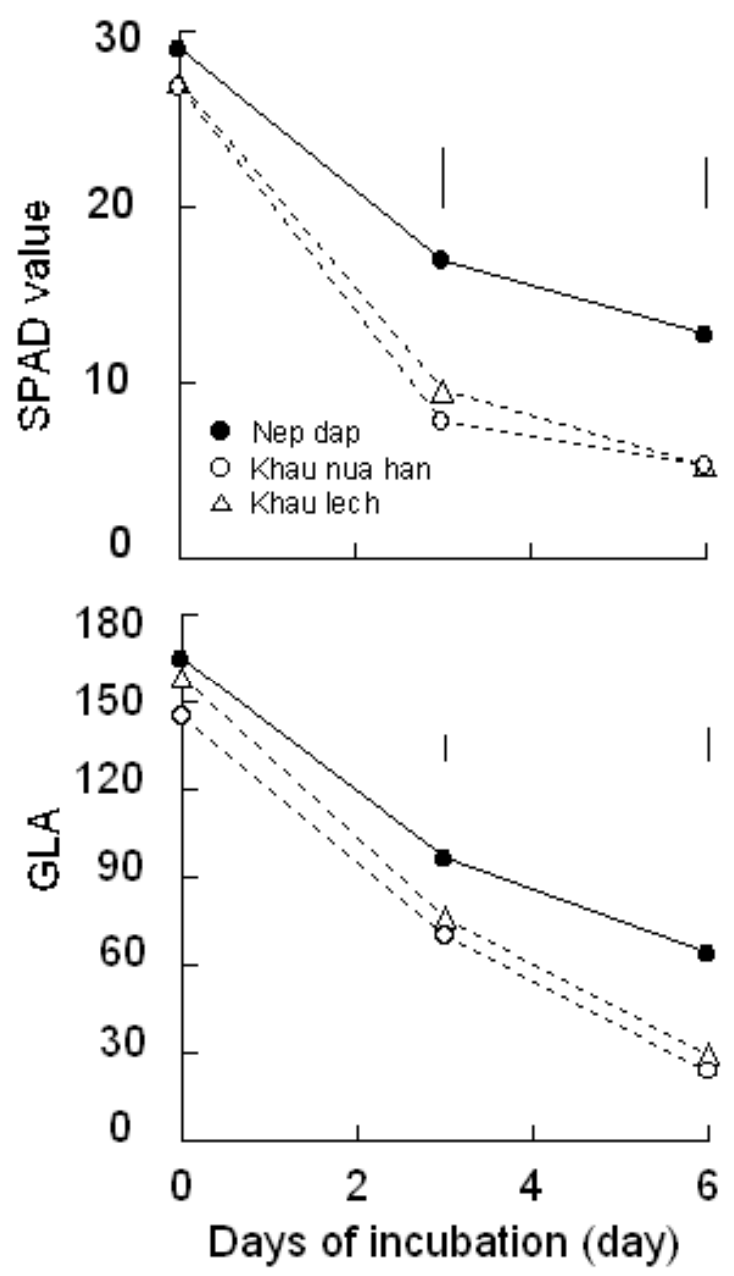

Fig. 7. SPAD value and green leaf area (GLA) in detached leaves incubated in a dark and humid condition for 6 days after heading in three Vietnam rice cultivars, Nep dap, Khau nua han and Khau lech. Each data is mean \pm se for 3 replications. Vertical bar indicates $\mathrm{LSD}_{0.05}$ by Tukey test. 
hence maintenance of green leaves should strongly relate with the delay in the senescent rate as chlorophyll degradation occurs (Jones 1983).

In Nep dap, the root length density in the surface soil layer at maturity was significantly higher than in the other two cultivars (Fig. 3), and both the amounts of absorbed water and its rate per root length in all soil layers (Fig. 4) were highest among the three cultivars (Fig. 5). These results suggest that water extraction by roots was more efficient in Nep dap than in the other two cultivars. Only from our results it is not certain whether the leaf property that maintains green leaves or the root characteristic of being able to efficiently absorb water from soils contributes to the maintenance of green leaf areas and $\mathrm{C}_{\mathrm{L}}$. In rice, the root system is completed before heading and starts to decay thereafter (Yoshida and Hasegawa 1982, Harada and Yamazaki 1993). In our results, the roots were taken at harvest and it was thus unknown whether root distributions at heading or the root decay rate during the grain-filling period differed between stay-green and non stay-green cultivars.

Some hybrid sorghums could maintain higher green leaves under post-anthesis drought because of higher specific leaf nitrogen (Borrell et al. 2001). This results in increased radiation use efficiency and transpiration efficiency, which, in turn, allow more carbon and nitrogen to be allocated to the roots of stay-green hybrids during grain filling, thereby maintaining a greater capacity to extract nitrogen from the soil compared with senescent hybrids (Borrell et al. 2001). Although in our results direct relationships between water and $\mathrm{ni}^{-}$ trogen absorption by root systems were not shown, the efficient function of water absorption should relate with that of nitrogen because nitrogen $\mathrm{ab}^{-}$ sorption increases with an increase in transpiration under desiccated soils (Lahiri 1980).

It was suggested that water absorption by the roots in the stay-green cultivar was efficient and the leaf property in stay-green plays an important role in maintaining the function of the root to $\mathrm{ab}^{-}$ sorb water and nutrient from soils, and to maintain $\mathrm{C}_{\mathrm{L}}$ and plant production. Furthermore, it should be directly evidenced whether the leaf property keeping green leaves results in the efficient water and nitrogen absorption by roots.

\section{Acknowledgements}

Our thanks to Dr F. Adachi for his experimental supports on measurements of root length density and Dr. K. Kobayasi for his suggestions. We thank the National Institute of Agrobiological Science, Japan for providing seed materials for the studies. Tien Ba Hoang gratefully acknowledges the financial support from The Ministry of Education, Science, Sports and Culture of Japan. Parts of the research were received by the foundation of JSPS (Pioneering Research).

\section{References}

Ahmad, S., Kobata, T. and Takami, S. 1987. Leaf death and alteration of internal water relations in rice (Oryza sativa L.) in response to water deficits in the seedling stage. Jpn. J. Crop. Sci. 56: 582-588.

Barker, R. and Herdt, R. W. 1979. Rainfed lowland rice as a research priority- an economist's view. In Rainfed Lowland Rice: Selected Papers from the 1978 International Rice Research Conference. IRRI. 3-50.

Borrell, A. K., Hammer, G. L. and Douglas A. C. L. 2000a. Does maintaining green leaf area in sorghum improve yield under drought? 1. Leaf growth and $\mathrm{se}^{-}$ nescence. Crop Sci. 40: 1026-1037.

Borrell, A. K., Hammer, G. L. and Douglas A. C. L. 2000b. Does maintaining green leaf area in sorghum improve yield under drought? 2. Dry matter production and yield. Crop Sci. 40: 1037-1048.

Borrell, A. K. and Hammer, G. L. 2000. Nitrogen dynamics and the physiological basic of stay-green in sorghum. Crop Sci. 40: 1295-1307.

Borrell, A., Hammer, G. and Oosterom, E. V. 2001. Stay-green: A consequence of the balance supply and demand for nitrogen during grain filling? Ann. Appl. Biol. 138: 91-95.

Christopher, J. T., Borrell, A. K., Manschadi, A. M., Hammer, G. and Chapman, S. 2004. Developing high yielding wheat for water limited environments in northern Australia. 4th International Crop Science Congress.

Dexter, A. R. and Woodhead, T. 1985. Soil mechanics in relation to tillage, implements, and root penetration in lowland soils. In: Soil Physics and Rice. IRRI, Los Banos, Philippines, pp. 261-281.

Gregory, P. J. 1994. Root growth and activity. In: Boote, K. J., Bennett, T. R., Sinclair, T. R. and Paulsen, G. M., Eds., Physiology and Determination of Crop Yield. ASA, CSSA amd SSSA. Wisconsin, USA.

GSO (General Statistic Office of Vietnam). 2007. Planted 
area and production of paddy. http://www.gso.gov.vn. Harada, J. and Yamazaki, K. 1993 Roots. In: Matsuo, T. and Hoshikawa, K., Eds., Science of the Rice Plant, Morphology. Food and Agriculture Policy Research Center, Tokyo, Japan, 1: 133-186.

Hasegawa, S., Thangaraj, M. and O’Toole, J. C. 1985. Root behavior: Field and laboratory studies for rice and non-rice crops. In: Soil Physics and Rice. International Rice Research Institute, Manila, Philippines, pp. 383-395.

Hirasawa, T., Iida, Y. and Ishihara, K. 1989. Dominant factors in reduction of photosynthetic rate affected by air humidity and leaf water potential in rice plants. Jpn. J. Crop Sci., 58: 383-389.

Hoang, T. B. and Kobata, T. 2009. Stay-green in rice (Oryza sativa L.) of drought-prone areas under desiccated soils. Plant Prod. Sci. in press.

Jones, H. G. 1983. Plants and Microclimate. A quantitative approach to environmental plant physiology. Cambridge University Press, Cambridge, UK.

Kimura, K., Kikuchi, S. and Yamasaki, S. 1999. Accurate root length measurement by image analysis. Plant and Soil, 216: 117-127.

Kobata, T., Okuno, T. and Yamamoto, T. 1996. Contributions of capacity for soil water extraction and water use efficiency to maintenance of dry matter production in rice subjected to drought. Jpn. J. Crop Sci. 65: 652-662.

Lahiri, A. K. 1980. Interaction of water stress and mineral nutrition on growth and yield. In: Turner, N. C. and Kramer, P. J., Eds., Adaptation Of Plants To Water And High Temperature Stress. New York, USA: John Wiley \& sons, pp. 341-352.

Mahalakshmi, V. and Bidinger, F. R. 2002. Evaluation of stay-green sorghum germplasm lines at ICRISAT. Crop Sci. 42: 965-974.

Milthorpe, F. L. and Moorby, J. 1979 An Introduction of
Crop Physiology. Second edition, Cambridge University Press, Cambridge, UK.

O'Toole, J. C. and Chang, T. T. 1979. Drought resistance in cereals-rice: a case study. In: Mussel, H., Staples, R. C., Eds., Stress Physiology in Crop Plants. New York, USA: Jonh Wiley \& sons. Pp. 373-406.

Samson, B. K., Hasan, M. and Wade, L. J. 2002. Penetration of hardpans by rice lines in the rain-fed low ${ }^{-}$ lands. Field Crops Res. 76: 175-188.

Sharma, P. K. and De Datta, S. K. 1985. Puddling influence on soil, rice development, and yield. Soil Sci. Soc. Am. J. 49: 1451-1457.

Tanner, C. B. and Sinclair, T. R. 1983. Efficient water use in crop production: Research or re-search? In: Limitations to Efficient Water Use in Crop Production. Taylor, H. M., Jordan, W. R., Sinclair, T. R., Eds., Am. Soc. Agron., Madison, WI, pp. 1-27.

Thangaraj, M., O’ Toole, J. C. and De Datta, S. K. 1990. Root response to water stress in rainfed lowland rice. Exp. Agric. 26: 287-296.

Thomas, H. and Smart, C. M. 1993. Crops that stay green. Ann. Appl. Biol. 123: 193-219.

Thomas, H. and Howarth, C. J. 2000. Five ways to stay-green. J. Exp. Bot. 51: 329-337.

Turner, N. C. 1979. Drought resistance and adaptation to water deficits in crop plants. In: Mussel, H., Staples, R. C., Eds., Stress Physiology in Crop Plants. New York, USA: John Wiley \& sons, pp. 343-372.

VietnamNews, 2007. Drought threat casts shadow on agriculture. http://vietnamnews.vnagency.com.vn. Last updated 4th Jannuary 2007.

Yoshida, S. 1981. Fundamentals of Rice Crop Science. IRRI, Philippines, 65-67.

Yoshida, S. and Hasegawa, S. 1982. The rice root system: its development and function. In: Drought $\mathrm{Re}^{-}$ sistance in Crops with Emphasis on Rice. IRRI, Philippines, pp. 97-114. 